\title{
Borges y la metafísica tanguera en Fervor de Buenos Aires*
}

Fecha de recepción: 20 de febrero de 2020

Fecha de aprobación: 30 de mayo de 2020

\section{Resumen}

Jorge Luis Borges encontró en la profundidad existencial del tango una fuerza expresiva y trascendental que cristalizó en su obra. Este artículo propone el examen de la relación tiempo y espacio que, desde el tango, compone en el poemario Fervor de Buenos Aires, de autor argentino. Desde los planteamientos del mismo Borges acerca del tiempo, fundamentos metafísicos, aproximaciones al tango y a la obra borgesiana, este artículo estudia la recuperación del espacio perdido a través de la revaloración poética del tiempo, muy al estilo del tango, en los poemas de Fervor de Buenos Aires. Así, en esta obra se poetiza el movimiento interior que el sujeto lírico, como el sujeto del tango, efectúa para rescatar la identidad del instante. En consecuencia, Borges despliega una comprensión metafísica de los lugares emblemáticos del tango, razón por la cual su concepción del tiempo no es ubicua y el sujeto de sus poemas, como el de los tangos, está volcado al encuentro con ideas intemporales de los espacios perdidos.

Palabras clave: Borges; Fervor de Buenos Aires; metafísica; tango; tiempo.

Citar: Orduz Rodríguez. F. (julio- septiembre de 2020). Borges y la metafísica tanguera en Fervor de Buenos Aires. La Palabra, (38), 77-89. Giohttps://doi.org/ 10.19053/01218530.n38.2020.10771

\section{Frank Orduz Rodríguez}

Docente en el Colegio INEM Carlos Arturo Torres, Tunja, Colombia. Magíster en Literatura, Universidad Pedagógica y Tecnológica de Colombia (UPTC), Licenciado en Español y Literatura, Universidad Industrial de Santander (UIS). frank.orduz.r@gmail.com.

(D)https://0000-0001-8959-8325

* Artículo de reflexión. 


\title{
la palabra
}

\section{Borges and Tango Metaphysics in Fervor de Buenos Aires}

\begin{abstract}
Jorge Luis Borges found an expressive and transcendental force in the existential depth of tango that is crystallized in his work. This paper proposes the examination of the relationship between time and space that, from tango, composed in Fervor de Buenos Aires, by Borges. From Borges' own approaches to time, metaphysical foundations, approaches to tango, and Borgesian work, this paper examines the recovery of lost space through the poetic revaluation of time, very tango-style, in the poems of Fervor de Buenos Aires. In Fervor de Buenos Aires, the inner movement that the lyric subject, like the subject of tango, makes to rescue the identity of the instant is poetize. Consequently, Borges displays a metaphysical understanding of the emblematic places of tango, the reason why his conception of time is not ubiquitous and the subject of his poems, similar to the tangos, is turned to the encounter with timeless ideas of lost spaces.
\end{abstract}

Keywords: Borges, Fervor de Buenos Aires, metaphysics, tango, time.

\section{Borges e a metafísica tanguista em Fervor de Buenos Aires}

\section{Resumo}

Jorge Luis Borges encontrou na profundidade existencial do tango uma força expressiva que cristalizou na sua obra. Este artigo propõe um exame da relação tempo e espaço que, a partir do tango, compõe o livro de poemas Fervor de Buenos Aires, do autor argentino.Com base nos conceitos de Borges acerca do tempo, nos fundamentos metafísicos, nas aproximações ao tango e na obra borgiana, este artigo estuda a recuperação do espaço perdido por meio da revalorização poética do tempo, ao estilo do tango, nos poemas de Fervor de Buenos Aires. Assim, em Fervor de Buenos Aires se poetiza o movimento interior que tanto o sujeito lírico quanto o sujeito de tango efetuam para resgatar a identidade do instante. Portanto, Borges desenvolve uma compreensão metafisica dos lugares emblemáticos do tango, razão pela qual sua concepção do tempo não é ubíqua e o sujeito dos seus poemas, e o dos tangos, se dispõe ao encontro com ideias intemporais nos espaços perdidos.

Palavras-chave: Borges, Fervor de Buenos Aires, metafísica, tango, tempo. 
«Esos muertos viven en el tango» - Jorge Luis Borges«(...) Hay también tristeza de arrabal, y rencor de horario y de jornal. Desazón de llorar lo que fue y mirar lo que llegó sin poderlo comprender (...)» -Homero Manzi-

El tango fue para Borges un objeto de análisis tan serio como la misma filosofía o la literatura, podemos dar solo un vistazo al estudio que hace de Evaristo Carriego, leer o escuchar sus charlas sobre tango en distintos escenarios, para respaldar esta afirmación. Su concepción acerca de esta expresión cultural y artística permeó gran parte de su obra, por lo que títulos como Hombre de la esquina rosada (1927) o Fervor de Buenos Aires (1923) se convirtieron no solo en obras que tocan la temática tanguera, sino en referentes del mismo tango ${ }^{1}$. Aunque Gobello (1980) comenta que Borges prefirió el tango del compa- drito, quizá porque disentía del tango postcontursiano (p. 223), esto no es del todo cierto, más por el acontecimiento que resulta ser su primera obra poética: Fervor de Buenos Aires, en la que nos presenta una comprensión metafísica de los lugares más emblemáticos del tango: su pérdida, su recuperación y su prevalencia temporal en el alma del sujeto del tango. Lo que viene de este escrito marchará tras un examen de dicha pérdida y la recuperación del espacio a través de una revaloración del tiempo, cuestión que se puede leer en el poemario mencionado, como en la poética del tango; aspecto que el mismo Borges abordaría luego en su Nueva refutación del tiempo - parte del volumen titulado Otras inquisiciones $(1952)^{2}$ -

Desde las lecturas de Schopenhauer, Berkeley y Hume, entre otros idealistas, Borges (2014b) puntualiza que el tiempo no es meramente ubicuo. Al contrario de lo que piensa Hume, sobre que hay muchos espacios - no uno absoluto - en un solo tiempo, Borges arguye que no existe un solo tiempo en el que "se eslabonan todos los hechos", en infinidad de espacios. Para el autor argentino: "Cada instante es autónomo" y, desde una perspectiva intelectualista, cada acontecimiento percibido por la razón es convertido en una idea, intemporal y, a su vez, parte del tiempo. Así, el tiempo es hacedor y evocador de infinidad de espacios y tiempos, en una serie temporal divisible, ya sea en presentes - efímeros- que se escinden, en pasados y en futuros (pp. 125-127).

En el caso de los poemas de Fervor de Buenos Aires y de las letras de tango, las dos expresiones plantean un sentimiento de pérdida reseñada en variedad de estudios $^{3}$. Esa pérdida del pasado, presente, y quizá futuro, que experimenta el sujeto del tango, como en los poemas de Fervor de Buenos Aires, es una pérdida parcial y que causa dolor de su

Un ejemplo claro es que textos y enciclopedias acerca del tango ven como ineludible asunto hablar de la concepción borgesiana del tango, ya sea porque el mismo Borges es un crítico o posible teorizador del tango, o porque parte de su obra, en sí, es un tango poema, si no es que los tangos son poemas y, en consecuencia, Borges sería un letrista de tangos. Un texto insigne del tango y que le abre un espacio al escritor argentino es precisamente Crónica general del Tango (1980), de José Gobello, importante tanto por su contenido como por la figura que representa su autor.

2 La tesis es del mismo Borges y la plantea en su ensayo objeto de esta disertación; incluso nombra poemas de Fervor de Buenos Aires en los que puede hallarse la noción de tiempo que propone. De igual forma, Borges formula, pese a la poca satisfacción producida por sus escritos y poemas, que la noción de tiempo que otrora inscribiera en estos escritos y poemas es quizá, a su criterio, una mala proyección en términos literarios. A su vez, cabe mencionar el juego con que Borges plantea su tesis, al afirmar que: "es tan antigua como la flecha de Xenón o como el carro del rey griego, en el Milinda Pañha" (Borges, 2014b, p. 121). Su intención, claramente es la de darle de antemano el carácter intemporal a su juicio; maniobra argumentativa tan inteligente como humorística.

3 Por ejemplo, está Tango testigo social (1999), de Andrés Carretero, que, entre un recuento sobre las mareas sociales, políticas, culturales y económicas en las que se gestó el tango, afirma que tanto literatura como historia concuerdan en que el tango es una amalgama de descontento, de protesta y de desorientación. El estudio de Javier Osorio Fernández, "Caminito que el tiempo ha borrado ... el tango y la experiencia de la modernidad. Argentina 1880-1930" (2003), es tal vez una gran introducción a la comprensión de ese sentimiento de pérdida tan propio de la modernización en Argentina, y que se solidificaría en el tango: una expresión tan fuerte que se constituyó en una voz resignificadora de los procesos modernizantes. Bien lo resume Osorio Fernández cuando afirma que: "En las letras del tango esta transformación es vista a través de imágenes del abandono o de la pérdida” (p. 90). 
dimensión humana, de su espacio y de su tiempo, pero que de ninguna manera lo despoja de su identidad; y por el contrario, le aporta a la construcción de la misma. En el tango, dice Eduardo Tijeras (1963), el sujeto pasa de la nostalgia a la queja - a la insatisfacción-, sentimiento que termina por identificar una colectividad que vive su pasión en lo perdido (p. 315).

Tales pérdidas vitales que experimenta el sujeto del tango, como también las experimenta el sujeto de los poemas de Fervor de Buenos Aires, las señala Sábato en su ineludible Tango, discusión y clave (2005):

El crecimiento violento y tumultuoso de Buenos Aires, la llegada de millones de seres humanos esperanzados y su casi invariable frustración, la nostalgia de la patria lejana, el resentimiento de los nativos contra la invasión, la sensación de inseguridad $\mathrm{y}$ de fragilidad en un mundo que se transformaba vertiginosamente, el no encontrar un sentido seguro de la existencia, la falta de jerarquías absolutas, todo eso se manifiesta en la metafísica tanguística. (p. 28) [...] El hombre del tango es un ser profundo que medita en el paso del tiempo y en lo que finalmente ese paso nos trae: la inexorable muerte. (p. 31)

El ser del tango no cuenta con una realidad estable más que la de sus nostalgias, no obstante, la poesía del tango, como bien lo apunta Rafael Flores, anda tras lo fugitivo y en un acto sacralizador y epifánico hace de la calle y de sus pérdidas algo perdurable a través del arte (1987, pp. 100-101). Y todo esto ocurre en el sujeto del tango, mientras que el yo del himno de arrabal, observador por excelencia de su entorno, hace arte con su llanto, a la vez que formula lo que Sábato nombra como el "mal metafísico", que el mismo autor de El túnel refuerza al citar a Nietzsche, cuando asiente que la metafísica está: "en medio de la calle, en las tribulaciones del pequeño hombre de carne y hueso" (2005, p. 28).

De modo que, tangos tan emblemáticos como «Caminito» (Filiberto y Coria Peñaloza, 1926), evidencian los sentimientos que brotan a causa del cambio del paisaje urbano; sentimientos que, cantados en primera persona, recalcan el sentir de un sujeto colectivo. Aún más contestatarios, tangos como «Cam- balache» $»^{4}$ (Discépolo, 1934) increpan la realidad corrompida a causa de "la sensación de inseguridad y fragilidad" de la que habla Sábato. Estos sentimientos que acusa el tango son quizá la quintaesencia del argentino y es el referente al cual Borges invita a reflexionar, a lo mejor para pertenecer a un pasado imaginado que encarnara su esencia argentina (Thon, 2010, p. 122). En el caso de Fervor de Buenos Aires, como bien lo plantea Ruth L. Conzelman Simms (1952),

[...] Borges perpetúa su esencial argentinidad, marca bonaerense. Pertenece al arrabal, patria chica de la ciudad. Es el hombre callejero, el cantor de barrio, el portefio. El poema de su vida y de su muerte está concentrado en el Fervor de Buenos Aires, una especie de ciudad eterna en su sentir. (p. 415)

"El poema de su vida y de su muerte" es una conclusión que revela que en Fervor de Buenos Aires se ponen en juego dos principios trascendentales del sentir porteño. Estos principios se explayan en cada uno de sus versos y, a la vez, salpican referentes inmateriales y materiales de una iconografía infra-

\footnotetext{
$4 \quad$ Según Juan Montero Aroca (2013), en Historia del tango canción (1917-1967. Los años de oro), Enrique Santos Discépolo escribe «Cambalache» para la película Alma de bandoneón (1935). La única canción que para esa película fue compuesta en solitario por Discépolo contaba con un toque especial: era uno de los precursores de aquellos tangos que difundían los síntomas de una sociedad enferma. Lo interesante de esto es que ante el desencanto de la sociedad que retrataba, tras el desastre económico de inicios de la década de 1930, «Cambalache», con el tiempo, se fue convirtiendo en parte de las letras del repertorio nacional argentino, aunque el sentido de su letra guarda valores universales.
} 
nacional ${ }^{5}$ eternizada. Es precisamente esta perpetuación de la ciudad, de su patria personal, la que interesa ver en relación con la noción borgesiana de tiempo, poetizada muy al estilo y espíritu del tango.

Desde lo anterior, la pérdida del pasado es evidente en poemas como "Calle desconocida", que en Fervor de Buenos Aires se lee:

Penumbra de la paloma

llamaron los hebreos a la iniciación de la tarde

cuando la sombra no entorpece los pasos

y la venida de la noche se advierte

como una música esperada y antigua,

como un grato declive.

En esa hora en que la luz tiene una finura de arena, di con una calle ignorada, abierta en noble anchura de terraza,

cuyas cornisas y paredes mostraban

colores tenues como el mismo cielo

que conmovía el fondo.

Todo - la medianía de las casas,

las modestas balaustradas y llamadores, tal vez una esperanza de niña en los balcones-

entró en mi vano corazón con limpidez de lágrima.

Quizá esa hora de la tarde de plata

diera su ternura a la calle, haciéndola tan real como un verso

olvidado y recuperado.

Sólo después reflexioné

que aquella calle de la tarde era ajena,

que toda casa es un candelabro

donde las vidas de los hombres arden

como velas aisladas,

que todo inmediato paso nuestro

camina sobre Gólgotas. (2014a, p. 22).

En principio, el poema se divide en tres momentos de un entramado argumental: el encuentro, el escrutinio y el hallazgo. Luego de filtrar su experiencia a través del recuerdo de la luz, esa que se mantiene en la eternidad de todas las tardes, halla la calle de estos versos: "[...] En esa hora en que la luz / tiene una finura de arena, / di con una calle ignorada, $[. .$.$] ". Lo que viene$ del poema es una descripción corta, pero sistemática — sin duda sensibilizada - de dicha calle, para luego ser escrutada por el yo del poema: “[...] entró en mi vano corazón / con limpidez de lágrima. / Quizá esa hora de la tarde de plata / diera su ternura a la calle, / haciéndola tan real como un verso / olvidado y recuperado [...]". El poema, que maneja una estructura creciente y argumentativa, determina al objeto de su percepción y luego lo comprueba, a través de su sensibilidad, como propio o ajeno. Desde el título parece, ya cantado, que en la calle observada no hay más que ajenidad: “[...] Sólo después reflexioné / que aquella calle de la tarde era ajena [...]".

Borges increpa el presente de la ciudad, con poco énfasis en eventos de un pasado reseñable, y son sólo inflexiones verbales las que insinúan que atrás hay algo que aún se puede ver. Pero más importante es que el autor argentino en "Calle desconocida", como en los demás poemas de Fervor de Buenos Aires, "exorciza" el espectáculo de modernización al que asiste, tal vez, en una defensa de la idea de nación, como lo propone Julio Pimentel (1999, p. 89), a la vez que ordena mentalmente ${ }^{6}$ este espectáculo de lo perdido. Sin embargo, poco hay en Borges del tremendo estallido de ruidos industriales y de la indistinguible masa, como sí el descubri-

Se le pude llamar así a la iconografía del tango, pues esta expresión es parte de un movimiento contracultural que se gestó en las clases obreras, y que desde la periferia logró generar una voz capaz de sacudir los sectores aristócratas, oligárquicos e intelectuales (Brito García, 1984).

6 Juan Gustavo Cobo Borda es quien ha planteado que la narrativa de Borges perfila "la serena alegría de un orden mental que transformaba el incipiente caos urbano" (1999, p. 123). Considero que los poemas de Borges no están exentos de dicha tendencia esquemática, que ciertamente es una afortunada "Inteligencia sensible", tal como Cobo Borda titula su ensayo, ahora reseñado. 
miento interior de la pérdida de un espacio vital.

En "Calle desconocida" la cuestión con el tiempo se nos enseña a través del vínculo intelectual que el sujeto establece con su actualidad, la misma que, como se ha mencionado, se cimienta en el argumento de la pérdida. Es justamente mediante el rescate del tiempo que el espacio perdido recobra parte de su esencia; es por tanto una cuestión puramente metafísica. Heidegger (2016) reconoce dicho carácter metafísico cuando concibe que el sujeto - para el caso, sea el del tango como el de los poemas de Borges - tiende a ponerse a sí mismo como parte de su interrogante por el tiempo y el espacio, como también por ir, en dicho ejercicio, más allá de lo dado. Pero aún más explícito es el filósofo alemán cuando en Ser y tiempo (2005) deriva en que, si el ser se concibe a partir del tiempo - temporaria-, este carácter no es exclusivo de "lo que está en el tiempo", y que lo constituyen también lo "intemporal" y lo "supratemporal" - lo eterno-, determinaciones originaras del sentido del ser el dasein- (p. 43).

Dar un vistazo al poema "Barrio recuperado" para comprender como el sujeto tanguero de la poética borgesiana, desde su perspectiva metafísica, como lo anota Robin Lefere (2005), se lanza en una aventura espiritual, en aquel espacio-tiempo "privilegiado" del ensueño (pp. 220-221). Ese espacio-tiempo "privilegiado" es el instante, tan único que, como ensueño, y en términos de Bachelard (2000), marca al ser en su profundidad, a la vez, que dicho ensueño le restituye el espacio en otro ensueño. Justamente, el rico oasis de la ensoñación da lo propio al tener "incluso un privilegio de autovalorización" del objeto ensoñado (p. 29). Ver entonces aquel otro ensueño que propone el tango:

Nadie vio la hermosura de las calles

hasta que pavoroso en clamor se derrumbó el cielo verdoso en abatimiento de agua y de sombra.

El temporal fue unánime

y aborrecible a las miradas fue el mundo,

pero cuando un arco bendijo con los colores del perdón la tarde,

y un olor a tierra mojada

alentó los jardines,

nos echamos a caminar por las calles

como por una recuperada heredad,

y en los cristales hubo generosidades de sol

y en las hojas lucientes

dijo su trémula inmortalidad el estío. (Borges, 2014a, p. 28)
Ese aguacero - desarreglando la bella metáfora de Borges-, el "temporal", es un evento purificador, acontecimiento presente en el que el yo lírico, con el sol que abre el verano y el arcoíris, como portón del ensueño, retorna a su "heredad". Por su parte, la heredad recuperada, en el sentido más fiel, es el lugar del barrio como también el conjunto de valores y prácticas que en este se realizan. En el poema, se muestra esa recuperación de la necesidad vital de caminar, experiencia que hermana al sujeto del poema con la recuperación del barrio y sus calles - como espacio que los vincula con un linaje determinado: el del sujeto del tango ${ }^{7}$ -

Borges explicaría la cuestión de la recuperación del tiempo luego en su Evaristo Carriego (1930), a través de la filosofía del truco, juego de cartas en el que la picardía y el engaño son lícitos. Se sabe que "El truco" es un poema de Fervor de Buenos Aires, que incluso su primer verso, con una leve modificación, le sirve para iniciar el sexto capítulo de Evaristo Carriego y es, precisamente, su cierre el que resulta muy clarificador para lo que se viene tratando: "[...] desde los laberintos de cartón pintado del truco, nos hemos acercado a la metafísica: única justificación y finalidad de todos los temas" (Borges,

Noemí Ulla (2013) plantea, entre varios aspectos, que tangos como «Yira... yira» o «Cambalache» narran ese vagabundeo vital del sujeto del tango; de hecho, compara al sujeto de las letras del tango con el Flâneur de Baudelaire: contemplativo, abarcador y creador (p. 183). 
2014a, p. 252). La razón es que Borges explica que el juego, que ya está arraigado en el alma y corazón del argentino, ya se ha convertido en la ficción que sustenta el mismo juego, en una serie de juegos pasados que se repiten, por ser jugadas y guiños a los que recurren sus jugadores en ejecuciones actualizantes. La cuestión metafísica yace aquí en volver a la identidad del instante $y$, en términos heideggerianos, en un acto de recuperación de un estado de pérdida:

El presente, que constituye el sentido existencial de ese «ser llevado», no gana nunca por sí mismo un horizonte extático diferente, a menos que en el acto resolutorio sea traído de vuelta de su estado de pérdida, para abrir, como instante retenido, la respectiva situación $\mathrm{y}$, junto con ella, la originaria «situación límite» del estar vuelto hacia la muerte. (Heidegger, 2005, p. 364)

"Barrio recuperado" o "El truco", como en el razonamiento de Borges -en Evaristo Carriego y en Nueva refutación del tiempo-, junto con los plantea- mientos de Heidegger, nos hablan de algo que ya sucumbió y que por un acto resolutorio de la sensibilidad es reconquistado ${ }^{8}$. Así como el epígrafe que abre esta disertación, lo muerto aparece restituido en letras como «Sur» (1948) o «Barrio de tango» (1942), las dos de Aníbal Troilo y Homero Manzi, donde las calles, ya sea en reflejos o en ecos de bandoneón o guitarras, retornan al lugar del barrio9. Así, el ser del tango, como el de los poemas de Fervor de Buenos Aires, está volcado hacia el encuentro con la muerte, no solo por sus nostalgias, que harían de todo puro recuerdo, sino por sus prácticas que sostienen su ethos y, en consecuencia, su relación con lo inmortal.

Por otro lado, los poemas de Fervor de Buenos Aires, como los tangos, crean una variedad de icónicos y espacios para asir el tiempo perdido. Es de esto que, los poemas crean una imagen apoteósica, legendaria o mitológica de los lugares eternos ${ }^{10}$, perdidos y arraigados en el alma del ser del tango, el cual se ve enfrentado al crecimiento de la ciudad y, con esto, a la pérdida de una proporción que le otorgaba una mayor cercanía con su espacio, así como con los demás habitantes del mismo. Incluso Borges (2016) recordaba que

[...] La ciudad era chica. Me dice mi madre que, por el norte, concluía en la calle Pueyrredón, que se llamaba Centroamérica entonces [...]. (p. 24)

[...] El doctor Bioy ${ }^{11}$ me dijo que él recordaba una época en la cual se sabía digamos... en la cual él conocía qué familia vivía en cada casa, de cada cuadra. (p. 25)

El relato, que es más extenso, hace parte de la primera de las cuatro conferencias sobre el tango que ofreció Borges en Barcelona, allí por 1965 . Además de entretenido y entrañable, revela no solo las proporciones pérdidas de lo que era la Buenos Aires de 1880, también muestra el distanciamiento sufrido entre los sujetos de la futura ciudad. Esta pérdida no sólo es física —material—, también es espiritual, en cuanto a que el movimiento de esta nueva época impide su relación habitual de cercanía con su entorno y los

8 El poema "Barrio recuperado" en la primera edición de Fervor de Buenos Aires se intituló "Barrio reconquistado", título que quizá recogiese aún mejor la epicidad de una lucha interior por la restitución de un territorio y de su valor temporal, y que en conformidad expresara la tenacidad de las maniobras redentoras del sujeto del poema y del tango.

9 Hernando Motato en su ensayo "La presencia del tango en El túnel" (2011), de Ernesto Sábato, plantea que el tango deja ver la vida del barrio, sus anhelos y todas las ilusiones que se le escapan al sujeto del tango, el lugar donde se despliega la reflexión de su dimensión metafísica (pp. 19-20).

10 Al respecto Julio Pimentel Pinto (1999) menciona que las imágenes de una Buenos Aires mitológica ayudan a recomponer su pasado urbano (p. 84) y, a su vez, citando a Beatriz Sarlo, confirma cómo el mito: “[...] evita la aceptación del cambio” (p. 91). Por su parte, Robin Lefere (2005) reconoce en Fervor de Buenos Aires un logro que antes, quizás, no estuviese tan cristalizado como en Borges: la inmortalidad poética de la ciudad de Buenos Aires (p. 213).

11 Se refiere al padre de su amigo y también escritor Adolfo Bioy Casares. 
sujetos que lo constituyen. Pero es justamente esta situación de despojo en la que el tiempo perdido - pasado - y el venidero —donde aparece el recuerdose ubican entre lo vivido y lo imaginado. Esto último es el giro borgesiano que indica que recordar no garantiza vivir el momento, como sí lo es llegar a la identidad de lo acaecido: "El tiempo, si podemos intuir esa identidad, es una delusión: la indiferencia e inseparabilidad de un momento de su aparente ayer y otro de su aparente hoy, basta para desintegrarlo" (Borges, 2014b, p. 128). Ante la situación planteada, en la construcción de un pasado imaginado o imaginario, el tiempo y el espacio están mezclados, "disueltos el uno en el otro" (Pimentel Pinto, 1999, p. 93).

Esa identidad del instante da pie para hablar de una fenomenología del arrabal, del patio, de las calles, del conventillo, de las orillas, del barrio, entre otros. El hecho de tal aseveración en los poemas de Fervor de Buenos Aires radica en cómo el sujeto de los poemas trasciende los lugares que describe, los perpetúa en su decir poético, los convierte en estados y confirma el mundo como una sustancia de la cual el hombre está hecho, citando al mismo Borges (2016, p. 133). Entonces, el hombre y el tiempo-espacio son uno, tan real como los poemas objeto de estudio o un tango. Por eso, la metafísica tanguera en los poemas de Fervor de Buenos Aires, ya establecida la función del espacio-tiempo como el problema del ser del tango, parte de una inmovilidad del sujeto sensible, anclado a la patria del barrio, de sus calles, de sus patios y casas, tal como la señala Bachelard (2000):

Habiendo franqueado los mil pequeños umbrales del desorden de las cosas polvorientas, los objetos-recuerdos ponen el pasado en orden. Se asocian a la inmovilidad condensada los más distantes viajes a un mundo desaparecido. En Milosz, ¡el sueño va tan lejos en el pasado que llega como a un más allá de la memoria! (p. 132)

El sujeto se ancla a la quietud que le permite recrear el instante; su encuentro con la inmensidad es fruto de "el movimiento del hombre inmóvil" (Bachelard, 2000, p. 164), el viaje de afuera hacia adentro, hacia lo que se niega a morir. Este viaje no es el recuerdo en simples términos "archivísticos", "no habita las casas del pasado", es, por el contrario, la pura "conciencia imaginante", la cual deja entrever "la divinidad del ser admirante" (pp. 163-164). Versos como: "Las calles de Buenos Aires / ya son mi entraña" (Borges, 2014a, p. 19), apuntan, entre su rico valor expresivo, a que este sitio, que representa el tránsito de su vida, es su esencia; no sólo el espacio es el mismo sujeto, también su historia en un ahora que es pasado y será futuro. Hay una fuerte conciencia de lo que es el instante, en la medida en que es el mismo sujeto el que lo encarna. La sugerencia de la sublimación entre el referente de un instante y el sujeto admirante es aún mucho más clara en cuanto a que las calles ${ }^{12}$ son lo que se lleva por dentro, son estas calles, como sus posibles trayectos, elemento identitario del sujeto y en efecto producto de la identidad del instante. Esta recuperación del tiempo y del espacio es un punto recurrente en los poemas de la antología de la que se ha venido tratando, además responde naturalmente al proceso catártico frente a la modernización en curso que

12 Cabe hacer una aclaración acerca de la naturaleza de las calles en relación con lo que dice de estas La poética del espacio (Bachelard, 2000). Dado que los planteamientos de Bachelard han servido para explicar el fenómeno temporal al que Borges se refiere, es de precisar que, aunque las calles son para el filósofo y epistemólogo francés un lugar de paso y, por ende, un lugar de mayor tranquilidad (p. 56), en el tango como en Borges las calles son una especie de patria personal, aportan una suerte de maniobrar reflexivo. Debido a que los orígenes del hombre del tango, a su condición heredada de inmigrante, el vagabundeo (revisar nota de pie de página número 7 de este articulo) lo faculta para ser un habitante constante de las calles, no un mero transeúnte. 
vivía entonces toda Latinoamérica $^{13}$.

En cuanto a los espacios que plantea Borges en sus poemas, es indiscutible la sublimación del ser con estos, aspecto que motiva el desencanto constante del ser del tango. En Borges este descontento es directo e indirecto, irónico y humorístico. En Fervor de Buenos Aires el descontento es nostálgico e introvertido como la misma danza del tango. En tal nostalgia, como el ensueño, todo se vuelve infinito e inconmensurable (Bachelard, 2000, p. 163), por lo que la inmensidad trastoca el espacio y lo prolonga en el tiempo. A este fenómeno de la sensibilidad se le podría pensar como un tipo de atemporalidad espacial, pues la riqueza de las acciones traspasa los límites ponderables del tiempo y reconquista, tanto en las mismas prácticas como los mismos espacios. Observemos los versos del poema "Despedida":

Entre mi amor y yo han de levantarse

trescientas noches como trescientas paredes

y el mar será una magia entre nosotros.

No habrá sino recuerdos.
Oh tardes merecidas por la pena,

noches esperanzadas de mirarte,

campos de mi camino, firmamento

que estoy viendo y perdiendo...

Definitiva como un mármol

entristecerá tu ausencia otras tardes. (Borges, 2014a, p. 52)

Cuando el sujeto del poema habla de recuerdos en sí habla de eternidades, de conciencias de un instante. Tardes, noches, campos son plurales que no indican limite, para al final cerrar con el monumento tallado en mármol. Vuelve la paradoja borgesiana de lo continuo y lo discontinuo, donde las tardes, las noches y los campos evidencian lo incesante - atemporal-, mientras lo estático, que a su vez está constituido por pasado, presente y futuro, ubicable en cualquier tiempo, no por los mecanismos de la sensibilidad, es consolidado a través del monumento.

El sujeto del poema "Despedida" eterniza la imagen de lo perdido y arrastra toda su riqueza al expandir las orillas del mar en que navega. La despedida, que en sí misma es dolorosa, se agudiza en la esperanza y en la simultaneidad del caminar hacia la ausencia, aspectos que, a la vez, garantizan que en otras tardes sentirá la ausencia. Entonces, la paradoja, tan basta en sentido, plantea que al faltar el espacio, no queda más que eternizarlo en la misma falta. Esto se asemeja quizás a "Sur", poema en el que se evocan barrios de Buenos Aires y, a su vez, el dolor por la partida:

San Juan y Boedo antiguo y todo el cielo,

Pompeya y, más allá, la inundación,

tu melena de novia en el recuerdo,

$y$ tu nombre flotando en el adiós...

La esquina del herrero barro y pampa,

tu casa, tu vereda y el zanjón y un perfume de yuyos y de alfalfa

que me llena de nuevo el corazón.

Sur... paredón y después...

Sur... una luz de almacén...

Ya nunca me veras como me vieras,

recostado en la vidriera

y esperándote,

ya nunca alumbraré con las estrellas

nuestra marcha sin querellas por las noches de Pompeya.

13 La modernidad como estilo de vida se había tomado a Buenos Aires, la cual no se resistía a tal transformación. Al respecto Beatriz Sarlo menciona que: "En la medida en que Buenos Aires se transformaba con una aceleración que pertenece al ritmo de las nuevas tecnologías de producción y transporte, la ciudad se convierte en condensación simbólica y material del cambio que despierta entusiasmos y desconfianzas inéditas: “Así se la celebra y también se la juzga."” (2007, p. 16). Luego señala que ante este panorama a Borges le interesaba, frente a la aceleración vertiginosa de crecimiento y olvido, una especie de recuperación de la cultura, de una forma imaginaria, otorgándole una nueva función al pasado (p. 32). 
Las calles y las lunas suburbanas

y mi amor en tu ventana

todo ha muerto, ya lo sé. (1948, Manzi y Troilo)

Nótese que en el poema y en el tango, tanto la ausencia como la partida, aunque parecieran definitivas, surgen como una reconstrucción de una nostalgia futura. El espacio y el tiempo, en tanto dimensiones de un idilio, son dados por perdidos, aun cuando no ha sucedido esta privación; y el yo lírico del tango, como el del poema, lo reafirma en el monumento de la pérdida, como también en el estoicismo de la comprensión de su suerte: "todo ha muerto, ya lo sé". Esta unidad de dos elementos que remarca lo muerto y lo monumental — sedimento de la existencia - son en poema y en canción una sublimación del sujeto, del espacio y del tiempo, un evento que enmarca una caracterización del ser que lo determina per se: un ser de nostalgia del pasado y del futuro.

Esta misma composición temporal fortalece la identidad del sujeto del tango que Borges, como letrista del tango, consolida en sus obras. Nótese que en el tango «Sur» el sujeto tiene la cualidad de las estrellas, alumbra con ellas, está sumido en la naturaleza del paisaje y no volverá a hacerlo bajo las condiciones de la partida. La ausencia del sujeto entonces es la ausencia de un paisaje, y el tiempo aquí, como el espacio, se ven destruidos. Lo interesante del poema de Borges es que la destrucción del tiempo y el espacio se ve conjurada por el recuerdo: "No habrá sino recuerdos", por lo que no hay dicha muerte $\mathrm{y}$, en otros términos, hay un monumento que recuerda la vida y la muerte de la experiencia que plantea el poema, la cual es un principio identitario del yo lírico: su actitud frente a la pérdida.

«Sur» es también el nombre de un poema de Fervor de Buenos Aires: "El sur", que demuestra todo lo que el ser del tango puede ser. A partir de un lenguaje sencillo y semánticamente explosivo, este poema sin duda enmarca parte de la cosmovisión del tango. Los dos primeros versos: "Desde uno de tus patios haber mirado / las antiguas estrellas, [...]" (Borges, 2014a, p. 21) examinan dos condiciones supratemporales que los lugares icónicos de la cultura del tango reflejan. La primera es la condición espacial del patio como lugar de la reflexión y la segunda es la conjunción con un ente que de antaño ha iluminado antiguos sujetos en el mismo patio. Es por lo que, el patio es el lugar de lo íntimo, propicio para la contemplación de esa intimidad tanguera. El patio, como espacio de lo interior, es "«el cuarto [que] está en nosotros" (2000, p. 196), según plantea Bachelard. Para tener certeza de que, es el patio un es- pacio por excelencia del tiempo de la reflexión, los mismos tangos lo cantan así:
¡Cuántas emociones acuden a mi alma /
$\mathrm{y}$ piden que las evoque en poesía, /
para nunca olvidar la dicha vivida /
en patios de aquellos días! /
[...] Tiempo sin reloj ni ur- gencia/
rescata cada patio salvado /
estilo grato de convivencia /
con celosa humildad guarda- do (s.f., Pilosof).

Y así se podría hablar de tangos como «Patio mío» (1953) de Cátulo Castillo y musicalizado por Aníbal Troilo : "Está mirando el cielo desolado / tu historia de ladrillos y portón...", con versos tan parecidos al de los poemas de Borges. Y sin precisiones astronómicas, el sujeto del tango mira el firmamento desde la quietud del patio, y, desde allí, al igual que la anécdota de Borges sobre la noche en Barracas, todo se repite:

Me sentí muerto, me sentí percibidor abstracto del mundo; indefinido temor imbuido de ciencia que es la mejor claridad de la metafísica. No creí; no, haber remontado las presuntivas aguas del Tiempo; más bien me sospeché poseedor del sentido reticente o ausente de la inconcebible palabra eternidad. (Borges, 2014b, p. 128) 
Y lo que es aún más apoteósico, el patio es pasión donde el ser trasciende, donde charla con su esencia y en el recuento de los días logra la búsqueda y el encuentro con lo esencial de su ser. Es el lugar perfecto para que la vida no sea demasiado pobre y sea inmortal — jugando con las palabras de Borges (2014b, p. 128).

Con todo, Jorge Luis Borges, muy al estilo de las letras del tango, rescata aquello que, tanto en sus poemas de Fervor de Buenos Aires como cualquier letra de Santos Discépolo o Enrique Candícamo, cualquier otro letrista de tango muestra: la pérdida de su espacio vital y su recuperación interior. Borges rescata la esencial bronca, la periferia rechazada, el sentimiento del barrio y el arrabal, ese "[...] reflejo de nuestro tedio. [...]" (2014a, p. 34), del tedio argentino. Asimismo, rescata la relación que el sujeto del tango establece con la trascendencia, a partir de la restauración de lo perdido, como la construcción de su propia esencia individual y colectiva. La metafísica tanguera en Borges es pues la reflexión del tiempo a través del espacio y la sublimación del ser con las dimensiones anteriores, las que hacen del sujeto del tango un sujeto espiritual, acreedor de una postura ética y estética que le hizo - y quizá le hace - la vida más llevadera en un panorama de decaimiento social. Fervor de Buenos Aires es pues la antesala de una poética tanguera trascendental que revela una traumática relación con los procesos de modernización, sobre todo con la pérdida del espacio vital y la recuperación de este mismo a través del encuentro con la identidad del instante.

\section{Referencias}

Bachelard, G. (2000). La poética del espacio (E. d. Champourcin, trad.). Buenos Aires: Fondo de Cultura Económica.

Borges, J. L. (2014a). Obras Completas 1923-1949, tomo I. Buenos Aires: Emecé.

Borges, J. L. (2014b). Obras Completas 1952-1972, tomo II. Buenos Aires: Emecé.

Borges, J. L. (2016). El tango: cuatro conferencias. Bogotá: Lumen.

Brito García, L. (1984). Cultura, contracultura y marginalidad. Nueva sociedad, (73), 38-47. Recuperado de https://nuso.org/media/articles/downloads/1188_1.pdf

Carretero, A. (1999). Tango, testigo social. Buenos Aires: Peña Lillo - Ediciones Continente S.R.L.

Cobo Borda, J. G. (1999). Borges: la inteligencia sensible. En Borges enamorado: Ensayos críticos. Diálogos con Borges. Rescate y glosa de textos de Borges y sobre Borges. Bibliografía (pp. 120-130). Bogotá: Instituto Caro y Cuervo.

Conzelman Simms, R. L. (1952). Un vistazo a la poesía de Jorge Luis Borges. Hispania, 35(4),415-418. https://doi.org/10.2307/335531 
Flores, R. (1987). Los letristas del tango y su ambiente. Cuadernos Hispanoamericanos, (99-104), 445. Recuperado de http://www.cervantesvirtual.com/buscador/?q=Los+letristas + del + tango+y+su+ambiente

Gobello, J. (1980). Crónica general del tango. Buenos Aires: Editorial Fraterna.

Heidegger, M. (2005). Ser y tiempo (J. E. Rivera, trad.). Santiago de Chile: Editorial Universitaria.

Heidegger, M. (2016). ¿Qué es metafisica? Bogotá: Editorial El Búho.

Lefere, R. (2005). Fervor de Buenos aires en contextos. Variaciones Borges, (19), 209-226. Recuperado de https://www.borges.pitt.edu/bsol/documents/1911.pdf

Montero Aroca, J. (2013). Historia del tango canción (1917-1967. Los años de oro). Valencia: Tirant lo Blanch Humanidades

Motato, H. (2011). La presencia del tango en El túnel. La Palabra, (19), 17-24. Recuperado de https:// revistas.uptc.edu.co/index.php/la_palabra/article/view/945

Osorio Fernández, J. (2003). Caminito que el tiempo ha borrado... el tango y la experiencia de la modernidad: Argentina 1880-1930. Anuario de Postgrado, (5), 75-95.

Pimentel Pinto, J. (1999). Borges lee Buenos Aires. Un ejercicio crítico frente a la modernización de la ciudad. Variaciones Borges, (8), 82-94. Recuperado de https://www.borges.pitt.edu/sites/default/files/0807.pdf

Sábato, E. (2005). Tango, discusión y clave. Buenos Aires: Editorial Losada.

Sarlo, B. (2007). Borges, un escritor en las orillas. Madrid: Siglo XXI.

Tijeras, E. (1963). Un ambiente de tango trascendido. Cuadernos Hispanoamericanos, (163-164), 314319. Recuperado de http://www.cervantesvirtual.com/obra/un-ambiente-de-tanto-trascendido/

Thon, S. (2010). La identidad lingüística argentina a través de Borges y Puig. Arbor, 186(741), 119-127. https://doi.org/10.3989/arbor.2010.741n1012

Ulla, N. (2013). Marginalidad y testimonio en las letras de tango. Gramma, 24(50), 175-185. Recuperado de https://p3.usal.edu.ar/index.php/gramma/article/view/2196

Tangos referenciados

Castillo, C. y Troilo, A (1953). Patio mío [Canción]. Buenos Aires T.K.

Manzi, H., y Troilo, A. (1942). Barrio de tango [Canción]. Buenos Aires RCA-Victor S.A.I.C. 
Manzi, H., y Troilo, A. (1948). Sur [Canción]. Buenos Aires RCA-Victor S.A.I.C.

Discépolo, E. S. (1934). Cambalache [Canción]. Editorial musical KORN S.A.I.C.

Pilosof, N. (s.f). El patio [Canción]. 